\title{
Actualización:
}

\section{Familias con un miembro con discapacidad}

Families with a member with disability

Paula Carrete*

\begin{abstract}
Resumen
En la evaluación de la discapacidad no solo se tiene en cuenta el déficit funcional de la persona sino que también se consideran los factores contextuales (ambientales y personales) que pueden afectar su salud y los estados relacionados con su salud.

La familia es la institución que más ayuda provee a las personas con discapacidad y la que se ve más afectada por este problema. Las personas con discapacidad tienen los mismos derechos que las personas sin discapacidad pero encuentran muchas más barreras y dificultades para ejercer estos derechos, lo que las pone en desventaja con respecto a los demás ciudadanos. El conocimiento de las leyes locales referidas a la discapacidad le permite al médico orientar a los pacientes y las familias con esta problemática. El médico de atención primaria puede ayudar a prevenir problemas relacionados con la situación de discapacidad como el abuso, el embarazo no deseado, el aislamiento familiar, el estrés del cuidador, etc.

La mirada que debería guiar el trabajo de los profesionales es la de la persona con discapacidad y la de su familia. Son ellos quienes viven la situación de discapacidad y conocen sus necesidades, que deberían determinar el rumbo de nuestra tarea diaria.
\end{abstract}

\section{Abstract}

The evaluation of disability not only takes into account functional deficit of in the person but also consider the contextual factors (environmental and personal) that may affect his health and his health-related states.

The family is the institution that provides assistance to people with disabilities and which is most affected by this problem.

People with disabilities have the same rights as people without them but find many more barriers and difficulties to execute their rights, which puts them at a disadvantage situation when they are compared with other citizens. Knowledge of local laws related to disability allows the physician to counsel patients and families with this problem.

The primary care physician can help to prevent problems related to the status of disability as abuse, unwanted pregnancy, family isolation, stress of the caregiver, etc.

We think we can guide our work thinking in our disabled patient and his family, because they are who experience the condition of disability and know their needs, which should determine the course of our daily tasks.

Palabras clave: discapacidad, legislación, abordaje familiar, diversidad. Key words: disability, legislation, family approach, diversity.

Carrete P. Familias con un miembro con discapacidad. Evid Act Pract Ambul. Ene-Mar 2012;15(1):26-29.

\section{Introducción}

Los progresos científicos y tecnológicos -que prolongan la expectativa de vida y la cronicidad de enfermedades que en el pasado llevaban rápidamente a la muerte-, el aumento de los casos de violencia, la influencia del alcohol y las drogas en las conductas humanas y la persistencia de la pobreza son factores que contribuyen, en mayor o menor medida, al origen de la discapacidad.

Este artículo está dirigido específicamente a despertar el interés de los profesionales de la salud sobre un tema cada vez más prevalente en atención primaria: la discapacidad.

"Discapacidad" es un término genérico que, a partir de un estado o condición de salud de una persona en interacción con su contexto, señala limitaciones en la actividad y restricciones en la participación

Esta definición, adoptada por la Organización Mundial de la Salud'1', implica un cambio de paradigma. La discapacidad ya no se aborda desde una mirada reduccionista, ya no se define por el déficit funcional de una persona, sino que también incluye los factores contextuales. Estos son aquellos que constituyen el trasfondo total de la vida de un individuo y de su estilo de vida. Incluyen los factores ambientales y personales que pueden afectar la salud, y los estados relacionados con la salud de la persona.

El funcionamiento y la discapacidad se conciben como una interacción dinámica entre la condición de salud (enfermedades, trastornos, lesiones, traumas, etc.) y los factores contextuales, de tal forma que si varía uno de ellos, el otro puede verse modificado, lo que conduce a que varíe el fun- cionamiento del individuo.

Por ejemplo, tomemos dos personas que, por una lesión traumática no intencional (ex accidente) que afectó su capacidad para caminar, deben desplazarse en silla de ruedas. Una de ellas trabaja en un edificio preparado con rampas y facilidades para el acceso y además cuenta con un automóvil con comandos manuales. La otra trabaja en un edificio inaccesible en una silla de ruedas y no sabe conducir, ha perdido su trabajo y ahora depende económicamente de sus padres (con las consecuencias anímicas que esto acarrea: ha perdido el deseo de hacer las cosas, ha abandonado su rehabilitación, etc.).

En estos ejemplos podemos ver claramente cómo el estado de salud de ambas personas es similar (las dos tienen discapacidad motora) pero sin embargo una de ellas tiene menos limitaciones en la actividad y menos restricciones en la participación que la otra.

El funcionamiento de estas personas es diferente porque los factores contextuales son diferentes (una cuenta con factores ambientales y personales favorables mientras que la otra no $)^{2}$.

Este enfoque permite tener una mirada más amplia a la hora de trabajar con personas con discapacidad y sus familias ${ }^{2}$. Si la discapacidad no es solamente una deficiencia, su solución (o mejoría) no depende solo del médico que diagnostica o prescribe medicaciones o algún tratamiento de rehabilitación sino de cualquier otro actor social que pueda aportar herramientas para mejorar la funcionalidad de la persona con discapacidad: enfermeros, docentes, cuidadores informales, arquitectos, urbanistas, diseñadores de productos de computación, fonoaudiólogos, asistentes sociales, etc. 
Por último y utilizando definiciones más clásicas, pero también útiles, podemos decir que la discapacidad se clasifica en motora, mental (intelectual o de la personalidad) o sensorial (incluye visual, auditiva y táctil). Según su duración, puede ser transitoria o permanente y según su intensidad, leve, moderada, severa y profunda.

\section{Epidemiología}

En 2002/3 se realizó en Argentina la primera Encuesta Nacional de Discapacidad (ENDI) complementaria del Censo Nacional de $2001^{3}$. Fueron encuestados 67.000 hogares ubicados en centros urbanos con más de 5.000 habitantes, considerando como hogar al conjunto de personas, parientes o no, que viven bajo el mismo techo y comparten los gastos de alimentación. De esa encuesta se desprenden los siguientes datos:

La institución que más ayuda provee a las personas con discapacidad es la familia. A su vez, la familia se ve afectada por la condición de discapacidad de uno de sus miembros, por lo tanto, es fundamental que los integrantes del sistema de salud le prestemos atención.

Esto implica diferentes objetivos: contener, acompañar, informar, prevenir aspectos específicos y mejorar la calidad de vida, tanto de aquellos con la discapacidad como de aquellos que no la tienen, pero conviven con ellos. Otros datos provenientes de dicha encuesta referidos a las causas de discapacidad en Argentina se resumen en el cuadro 1.

Cuadro 1: causas de discapacidad según la Encuesta Nacional de Discapacidad realizada en Argentina en 2002/3.

\begin{tabular}{l|c}
\multicolumn{1}{c|}{ Causa } & $\begin{array}{c}\text { Porcentaje de } \\
\text { personas con } \\
\text { discapacidad }\end{array}$ \\
\hline Enfermedad adquirida & $44,7 \%$ \\
\hline Congénita & $12,8 \%$ \\
\hline Lesiones traumáticas no intencionales (ex accidentes) & $12,3 \%$ \\
\hline Problemas del parto & $2,1 \%$ \\
\hline Enfermedades de la madre durante el embarazo & $0,9 \%$ \\
\hline Hechos violentos o desastres naturales & $1 \%$ \\
\hline Otras causas & $13,5 \%$ \\
\hline Más de una causa & $1,2 \%$ \\
\hline Ignora la causa & $9,2 \%$ \\
\hline Desconoce la causa & $2,3 \%$ \\
\hline
\end{tabular}

Fuente: Instituto Nacional de Estadística y Censo: Discapacidad. En: Instituto Nacional de Estadística y Censo. Disponible en URL: http://www.indec.gov.ar/principal.asp?id_tema=166 (último acceso 02/03/2012).

\section{Herramientas para atender a las familias con un miembro con discapacidad}

En la Facultad de Medicina se brinda poca formación sobre la discapacidad, y la poca que se brinda suele ser técnica y especializada, centrada en reparar la falta y corregir el daño, y no suele estar dirigida al abordaje de la familia y el contexto de la persona con discapacidad ${ }^{4}$.

-El médico de atención primaria cuenta con diferentes herramientas para ayudar a las familias con un miembro con discapacidad.

Obviamente, estas herramientas varían según su formación, el tipo de pacientes que atiende y el área donde trabaja.

Sin embargo, los médicos nos equivocaríamos si quisiéramos alcanzar el conocimiento y emular la tarea de los especialistas en discapacidad (p. ej. para la elección del bastón más adecuado para un determinado paciente está el médico fisiatra y/o el kinesiólogo; para definir la mejor alimentación para un paciente con parálisis cerebral están el nutricionista o el gastroenterólogo, etc.).

En definitiva, el lugar del profesional de atención primaria es el de aquel que puede tener una mirada más amplia, menos centrada en la persona con discapacidad y más en la familia, pero para poder ser eficaz debe tener conocimientos específicos y ser creativo.

Es importante que el médico de familia reconozca el problema, sepa que existen redes y regulaciones que protegen a los pacientes y a sus familias y que por otro lado, deben consultar y apoyarse en los trabajadores sociales.

\section{El certificado de discapacidad}

El certificado de discapacidad es un documento público que se otorga a toda persona que lo solicite y que tenga una alteración funcional permanente, transitoria o prolongada; física, sensorial o mental, que en relación con su edad y medio social implique desventajas considerables para su adecuada integración familiar, social o laboral (esto lo determina una junta médica).

En Argentina el certificado de discapacidad sirve para acceder a la cobertura integral de las prestaciones básicas de habilitación y rehabilitación (Ley 24.901) y a la cobertura integral de medicación (Ley 23.661) .

También facilita la realización de gestiones como: obtención de pase libre en transporte de pasajeros, exención del pago de patente, permiso para libre tránsito y estacionamiento, acceder a beneficios del régimen de asignaciones familiares en ANSES, obtener franquicias para la compra de automóviles, acceder a la administración de pequeños comercios y solicitar empleo en la administración pública.

El cuadro 2 resume la legislación argentina vinculada a la problemática de la discapacidad.

\section{El problema existe más allá de lo que se ve a simple vista en el consultorio}

La discapacidad puede estar en el consultorio pero puede pasar inadvertida si no la buscamos. Detrás de una mujer que no adhiere a las recomendaciones médicas puede haber una madre sobreexigida a causa de la discapacidad de su hijo, detrás de un adolescente deprimido puede haber un hermano de alguien con discapacidad sobreadaptado a las exigencias de la vida familiar, detrás de un hombre cansado puede haber un esposo sobrecargado por el cuidado de su esposa con alguna enfermedad limitante. Identificar estas situaciones permite redefinir los problemas de salud y utilizar otras estrategias para solucionarlos (mejorar la adherencia, la depresión y el cansancio)².

Para ello, es preciso que el médico tenga en cuenta la posibilidad de que su paciente conviva, quiera o cuide a una persona con una discapacidad y, por lo tanto, incorpore en su interrogatorio preguntas específicas y considere el tema al armar el genograma. Los médicos estamos acostumbrados a interrogar a nuestros pacientes acerca de antecedentes familiares de enfermedad vascular o de cáncer; casi siempre preguntamos hacia atrás: "¿alguno de sus padres tiene o tuvo diabetes?", 
Cuadro 2: principales leyes argentinas referidas a discapacidad.

\begin{tabular}{|c|c|}
\hline Ley & Áreas que legisla \\
\hline Ley 22.431 & ealiza una definición legal de la persona con discapacidad y explicita un sistema de protección integral de las personas discapacitadas. \\
\hline Ley 18.910 & Se refiere a la posibilidad de solicitar una pensión no contributiva por invalidez. \\
\hline Ley 20.475 & $\begin{array}{l}\text { Establece un régimen especial de previsión social para las personas con discapacidad. Se refiere a la posibilidad de jubilarse con } 20 \text { años de } \\
\text { servicio y } 45 \text { años de edad los trabajadores dependientes } 050 \text { años los autónomos. }\end{array}$ \\
\hline Ley 20.888 & Se refiere a la posibilidad de jubilarse a los 45 años de edad y/0 con 20 de servicio si se sufre una incapacidad visual adquirida en servicio. \\
\hline Ley 24.714 & Alude a la posibilidad de recibir una asignación por hijo de cualquier edad con discapacidad. \\
\hline Ley 24.716 & Se refiere a la posibilidad de tener una licencia especial por maternidad cuando el hijo tiene síndrome de Down. \\
\hline Ley 23.592 & Se refiere a castigos penales por actos discriminatorios. \\
\hline Ley 25.280 & $\begin{array}{l}\text { Ley por la que el Congreso Nacional aprueba la Convención Interamericana para la eliminación de todas las formas de discriminación contra las } \\
\text { personas con discapacidad, suscripta en Guatemala. Se refiere al derecho a no ser discriminado. }\end{array}$ \\
\hline Ley 23.661 & Se refiere a la cobertura integral (100\%) de los gastos de medicamentos y libre elección de prestadores.. \\
\hline Ley 22.431 y 23.876 & $\begin{array}{l}\text { Aluden a la posibilidad de solicitar un "pase libre" en el transporte público. El art. } 20 \text { de la ley } 22.431 \text { establece la prioridad de la supresión de } \\
\text { barreras físicas en los ámbitos urbanos arquitectónicos y del transporte con el fin de lograr la accesibilidad para las personas con movilidad } \\
\text { reducida y define el concepto de barreras físicas }\end{array}$ \\
\hline Ley 24.195 (art.5 inc. $\mathrm{k}$ ) & Se refiere al derecho a integrarse a la educación común. \\
\hline Ley 24.308 & $\begin{array}{l}\text { Se refiere al derecho a inscribirse a fin de obtener la concesión de un pequeño comercio en alguna sede administrativa o en las empresas privadas } \\
\text { que brinden servicios públicos. }\end{array}$ \\
\hline Ley 24.147 & Alude a la posibilidad de crear talleres de producción protegidos con ayuda económica estatal y beneficios impositivos. \\
\hline Ley 24.314 & Se refiere a la posibilidad de reclamar la plena accesibilidad al medio físico. Modifica a la ley 22431. \\
\hline Ley 19.279 & $\begin{array}{l}\text { Se refiere al derecho de poseer un símbolo internacional de libre tránsito y estacionamiento y luego solicitar la exención del pago de patentes del } \\
\text { automotor, adquirir un automotor nacional sin pagar IVA, o importado a valor del automóvil en su país de origen sin pagar impuestos (se debe tener } \\
\text { imposibilidad o dificultad para viajar en transporte público de pasajeros). Establece otros beneficios para la adquisición de un automotor. (por } \\
\text { ejemplo, una contribución del Estado para la adquisición de un automotor de industria nacional la que no superará el cincuenta por ciento del } \\
\text { precio al contado de venta al público del automóvil standard sin accesorios opcionales ni comandos de adaptación). }\end{array}$ \\
\hline
\end{tabular}

pero casi nunca preguntamos sobre el presente: “ ¿sus hijos son sanos? ¿Hay alguien en su familia que tenga un problema de salud o que tenga alguna discapacidad?".

Habitualmente damos por sentado que si los hijos o los hermanos de nuestros pacientes son jóvenes, son sanos. Es importante incorporar la búsqueda de familiares con discapacidad en el interrogatorio habitual del profesional de la salud.

\section{La discapacidad afecta a toda la familia}

Las familias con un miembro con discapacidad constituyen un grupo con riesgo de desarrollar problemas psicosociales, lo que no significa que inexorablemente los harán. Esto dependerá de la capacidad de la familia de poner en juego recursos, herramientas, medios que le permitan adaptarse, en cada momento, a la situación de discapacidad.

A lo largo de su ciclo vital, todas las familias atraviesan diferentes crisis, y aquellas con un miembro con discapacidad también lo hacen. En estas últimas, cada crisis reedita el duelo y el desafío de enfrentar las dificultades ocasionadas por la discapacidad no sólo en quien tiene la limitación, sino en los demás integrantes de la familia.

Más allá de las crisis vitales esperables en toda familia, el médico de atención primaria que atiende familias con un miembro con discapacidad puede hacer prevención en diferentes aspectos:

1) Deterioro de la función parental (muchas veces, los padres de niños con discapacidad quedan subordinados a las indicaciones de kinesiólogos, neurólogos, fonoaudiólogos y otros expertos, quienes probablemente se ocupan muy bien del niño enfermo pero pierden de vista que son los padres y hermanos quienes comparten más tiempo con él y quienes que más lo conocen);

2) Dificultades en la identificación de cuáles son las necesidades y limitaciones que tienen como familia y de las capacidades y limitaciones específicas que tiene la persona con discapacidad. De este modo, se pueden evitar la autoexigencia desmedida, las policonsultas agotadoras, el gasto ilimitado en tratamientos que no reditúan beneficios, la caída en manos de personas inescrupulosas que prometen curaciones mágicas;

\section{3) Embarazo no deseado.}

\section{4) Abuso o maltrato de la persona con discapacidad.}

\section{5) Estrés del cuidador.}

6) Falta de comunicación e información: en algunas familias sucede que un miembro determinado es el que asume la mayor responsabilidad del cuidado de la persona con discapacidad. El designado conoce los tratamientos realizados, los médicos consultados, entiende a la persona con discapacidad cuando esta tiene problemas de comunicación, se da cuenta si está triste o nerviosa, sabe qué remedios toma, qué comida tolera mejor, etc. y posee una información muy valiosa acerca de la persona con discapacidad. A veces, nadie más en la familia cuenta con esta información. La crisis comienza cuando esta persona (el "encargado") no puede ocuparse más de la situación, o fallece y con esa muerte se pierde toda la información referente a los cuidados de la persona con discapacidad;

7) Falta de tiempo recreativo de la familia y de la persona con discapacidad: es habitual que en las familias con un integrante con discapacidad la actividad familiar se organice en torno a él: llevarlo al kinesiólogo, al traumatólogo, al neurólogo, al terapista ocupacional, etc. El médico puede identificar y jerarquizar este problema e invitar a la familia a pensar estrategias que permitan encontrar un tiempo para el placer, el ocio y el encuentro recreativo personal y de la familia o de algunos de sus miembros, apostando a la salud mental de todos. Del mismo modo, ocurre con la persona con discapacidad, pero el problema se ve acrecentado porque debe cumplir con múltiples horarios que hacen que muchas veces las actividades de 
recreación (asistir a un cumpleaños, por ejemplo) queden postergadas por los turnos con los distintos especialistas;

8) Aislamiento familiar: siguiendo la línea del punto anterior, y acrecentado por sentimientos como vergüenza o culpa, la familia con un miembro con discapacidad puede aislarse, lo que deteriora su capacidad de sostén y puede afectar la salud mental familiar;

9) El futuro: en ocasiones, en estas familias hay temas que preocupan pero que quedan postergados o que se resuelven a medida que se va avanzando en la vida, pero que no se hablan. Si la persona con discapacidad es dependiente y, por ejemplo, es un menor, ¿quién se ocupará de ella en el futuro? Muchas veces, los hermanos quedan atrapados, sin desearlo ni saberlo, en este mandato de cuidado. El costo personal de esta "designación" puede reducirse si la familia es capaz de generar un espacio para hablar del futuro.

\section{Abordaje de la problemática de la familia con un miembro con discapacidad}

Para hacer prevención en estos aspectos el médico tiene que identificar el problema y convocar a la familia. Hay temas más fáciles de tratar (prevención del embarazo u organización del tiempo libre familiar) y otros más difíciles (abuso o maltrato). También hay profesionales de la salud más entrenados, que podrán abordar algunos de estos temas en su consultorio y otros menos entrenados, o con menor disponibilidad horaria o que por temas personales o por otras circunstancias preferirán derivar a la familia a un especialista en salud mental. Cualquier opción es correcta en tanto esté basada en las posibilidades personales de cada profesional; lo importante es conocer las vulnerabilidades relacionadas con la discapacidad y aprender a identificarlas en las familias que uno atiende.

\section{Recursos comunitarios}

Recordando que a otras familias también les pasa, un elemento muy útil para acompañar a las familias con un miembro con discapacidad son las organizaciones no gubernamentales (ONG) y los grupos de autoayuda creados por personas o familiares de personas con un problema de salud específico. El número es grande, algunas funcionan muy bien, otras no tanto, pero lo importante es que sus integrantes ya han recorrido un camino y pueden alertar a los miembros nuevos sobre los atajos y los escollos de ese camino. En ese sentido, Internet representa una herramienta muy valiosa para encontrar contactos y ampliar la red personal; basta con escribir en cualquier buscador: "grupos de..." o "familiares de..." y surgen los datos y las páginas de diferentes entidades referidas a distintas enfermedades, que cuentan con grupos de contención y/o asesoramiento. Como siempre, en Internet es importante usar esa información con cautela y no proveer información personal que pueda ser utilizada en forma inadecuada.

\section{La creatividad}

Si hay una palabra que describe la discapacidad es la "diversidad". Ninguna discapacidad es igual a otra, así como ninguna persona es igual a otra. Esto es así porque los elementos que definen la condición de discapacidad son muchos: el tipo de déficit, su magnitud, la edad en que se adquiere, el momento en que se diagnostica, la historia de la persona, sus capacidades, las características de su personalidad, el lugar donde vive, si tiene o no familia, el lugar que ocupa en su familia, su situación personal en el momento en que adquiere la discapacidad, su entorno social, su situación económica, la red con la que cuenta, etc.

Esto determina que dos personas con la misma dificultad (p. ej. una discapacidad motora) desarrollen caminos diferentes y una se integre socialmente, sea autónoma y gestora de su vida, y otra dependa permanente y completamente de la ayuda de otros.

Por eso, la creatividad es un elemento importante en la atención de las familias de personas con discapacidad. Además de diseñar estrategias y servicios, hay que darle espacio a preguntas como: ¿qué necesita esta familia en particular?, ¿qué necesita esta pareja de padres?, ¿qué necesita la madre de esta persona con discapacidad?, ¿qué necesita su padre?, ¿y su hermano mayor?, ¿y el menor?

Lo más difícil es atrevernos a enfrentar las respuestas, aunque desde la medicina clásica suenen desafiantes o ridículas: los integrantes de estas familias necesitan integrarse con otras familias, necesitan contar un tiempo para estar solos, necesitan hacer algo que los divierta, necesitan apoyo para tomar una determinada decisión, necesitan un espacio para llorar, necesitan sentirse mejor, necesitan aceptar que no pueden con todo, necesitan poder ir al cine sin culpa, necesitan que sus padres dejen de mirar constantemente al hermano con discapacidad y miren a los otros hijos, necesitan aceptar su enojo con la situación, necesitan otro modo de comunicarse, etc.

En fin, necesitan que los profesionales de la salud los ayudemos a tratar de organizar el cuidado en función de sus necesidades y no en función de lo que a nosotros, desde nuestra mirada, limitada y externa, nos parece.

\section{Referencias}

1. Organización Mundial de la Salud. Discapacidades. En: Organización Mundial de la Salud. Disponible en URL: http://www.who.int/topics/disabilities/es/ (último acceso 02/03/2012).

2. Nuñez B. Familia y discapacidad, de la vida cotidiana a la teoría. Primera edición. Buenos Aires. Ed. Lugar, 2007.

3. Instituto Nacional de Estadística y Censo: Discapacidad. En: Instituto Nacional de Estadística y Censo. Disponible en URL: http://www.indec.gov.ar/principal.asp?id_tema=166 (último acceso 02/03/2012).

4. Pantano L. El protagonismo de la familia con al menos un miembro con discapacidad: una lectura a través de algunos datos cuantitativos. Revista Conceptos, Universidad del Museo Social Argentino. Año 80. Disponible en URL: http://www.umsa.edu.ar/downloads/publicaciones/conceptos/conceptos2-05.pdf (último acceso 02/03/2009).

5. Presidencia de la Nación. Obtención del certificado único de discapacidad: En Argentina.gob.ar: Guía del Estado. Disponible en URL: http://www.argentina.gob.ar/tramites/552-obtenci\%C3\%B3ndel-certificado-nico-de-discapacidad-cud.php 